\title{
Outbreak of Oropouche Virus in French Guiana
}

\author{
Mélanie Gaillet, Clara Pichard, Johana Restrepo, Anne Lavergne, Lucas Perez, \\ Antoine Enfissi, Philippe Abboud, Yann Lambert, Laurence Ma, Marc Monot, Magalie Demar, \\ Felix Djossou, Véronique Servas, Mathieu Nacher, Audrey Andrieu, Julie Prudhomme, Céline Michaud, \\ Cyril Rousseau, Isabelle Jeanne, Jean-Bernard Duchemin, Loïc Epelboin, ${ }^{1}$ Dominique Rousset ${ }^{1}$
}

Oropouche fever is a zoonotic dengue-like syndrome caused by Oropouche virus. In August-September 2020, dengue-like syndrome developed in 28 of 41 patients in a remote rainforest village in French Guiana. By PCR or microneutralization, 23 (82.1\%) of 28 tested patients were positive for Oropouche virus, documenting its emergence in French Guiana.

F rench Guiana is an overseas territory of France in northern South America; $95 \%$ of the country is covered by Amazon rainforest. The remote village of Saül, deep in the rainforest, had 152 permanent inhabitants in 2017 (INSEE, https:/ / www.insee.fr/fr/ statistiques/4271842), but the actual population in 2020 was 95 . The nurse of the health center keeps an updated count of inhabitants in the village, a number that was stable because of isolation during the coronavirus disease (COVID-19) pandemic. In August and September 2020, French Guiana was experiencing simultaneous COVID-19 and dengue outbreaks. Several inhabitants of Saül were treated for dengue-like symptoms, including fever and diffuse muscle pain, but rapid diagnostic testing for dengue was negative.

\section{The Study}

Saül houses 1 of 17 remote centers for prevention and care (RCPC) distributed throughout the inner

Author affiliations: Cayenne Hospital Center, Cayenne, French Guiana (M. Gaillet, C. Pichard, L. Perez, P. Abboud, Y. Lambert, M. Demar, F. Djossou, V. Servas, M. Nacher, C. Michaud, L. Epelboin); Collectivité Territoriale de Guyane, Cayenne (J. Restrepo); Institut Pasteur de la Guyane, Cayenne (A. Lavergne, A. Enfissi, J.-B. Duchemin, D. Rousset); Institut Pasteur, Paris, France (L. Ma, M. Monot); Santé Publique France, Cellule Régionale Guyane, Cayenne (A. Andrieu, J. Prudhomme, C. Rousseau); Health Regional Agency of French Guiana, Cayenne (I. Jeanne)

DOI: https://doi.org/10.3201/eid2710.204760 territories of French Guiana (Figure 1). On August 11, 2020, a 55-year-old patient from Saül sought treatment with a dengue-like syndrome (DLS) including a marked meningeal component but tested negative for dengue. The patient was hospitalized on August 22 in Cayenne, the territorial capital. Bacteriologic, virologic, and parasitologic investigations were inconclusive. The Saül RCPC reported 15 additional patients with dengue-negative DLS during August 22-September 7. Consequently, an investigation was scheduled to begin in Saül on September 16. Sociodemographic data, clinical manifestations and evolution, and biological samples were systematically collected for each new case and, when possible, retrospectively for patients who sought treatment for DLS symptoms during August 11September 16 (Appendix, https:/ / wwwnc.cdc.gov/ EID/article/27/10/20-4760-App1.pdf).

On September 22, because results of serologic testing for common locally circulating arboviruses were negative, we performed real-time PCR for Oropouche-like virus on all available samples collected $\leq 5$ days after the onset of symptoms (1). We performed viral isolations on Vero cells from PCRpositive samples and sequenced 1 isolate. Later, we performed microneutralization tests to complete biologic investigations on late serum samples. We collected clinical, biological, and anamnestic data, including localization (Figure 2), from medical and laboratory records (Appendix).

As part of the entomologic investigation, over a 48-hour period during September 30-October 2, we captured potential vectors by using 11 BG-Sentinel traps (Biogents, https://biogents.com), 5 CDC light traps (BioQuip, https://www.bioquip.com), and 1 Woodstream Mosquito Magnet trap (https://www. woodstream.com). Vector control measures, mostly aerial insecticide spraying and larval treatment, were

${ }^{1}$ These authors contributed equally to the work. 
only implemented 1 week later because of logistical constraints (lack of necessary aerial resources).

We obtained oral consent from patients to participate in the study and collected the biological samples as part of the care process. All data were collected on a standardized form and kept confidential to prevent disclosure of any personally identifiable information according to the requirements of the Commission Nationale de l'Informatique et des Libertés (https:/ / www.cnil.fr).

During August 11-October 15, 2020, DLS was diagnosed in 41 (of 95 total) residents of Saül who sought treatment at an RCPC. Median age was 38 years (range 3-82 years, interquartile range 16-51 years) (Appendix Table 1); male-to-female ratio was 1.6:1 (Appendix Table 2). We tested blood samples from 28 patients; 23 were confirmed positive for Oropouche virus (OROV), 7 by PCR alone, 12 by microneutralization alone, and 4 by both. For the other 5 patients sampled, we were unable to confirm the diagnosis in the absence of a later sample to test for seroconversion. In addition, 17 residents, including 8 children, later reported having experienced DLS during the study period but did not visit the RPCP and therefore were not included in the study.

We obtained 5 viral isolates on Vero cells from PCR-positive serum samples; sequencing 1 of these isolates confirmed OROV infection. The attack rate in the village population was $43.2 \%$ (41/95); however, including residents with DLS symptoms who did not seek medical help would make the actual attack

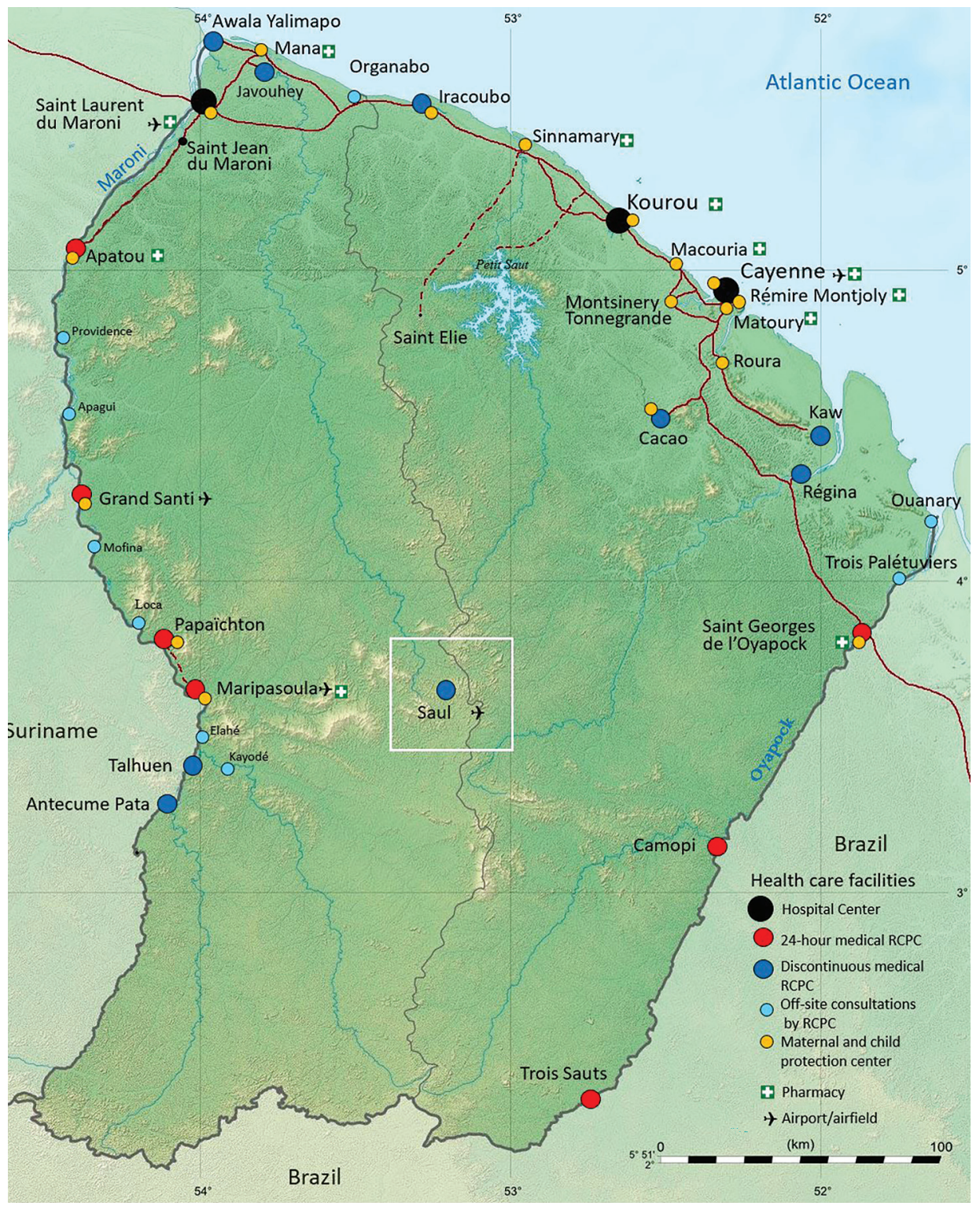

Figure 1. Locations of the town of Saül and 17 remote centers for prevention and care in French Guiana. Black circles: hospital centers; red circles: 24-hour remote centers for prevention and care; dark blue circles: remote centers for prevention and care (not 24-hour); light blue circles: off-site consultations with remote center for prevention and care; orange circles: maternal and child protection centers. Source: Dr. Elise Martin, Centre Hospitalier de Cayenne, French Guiana. 


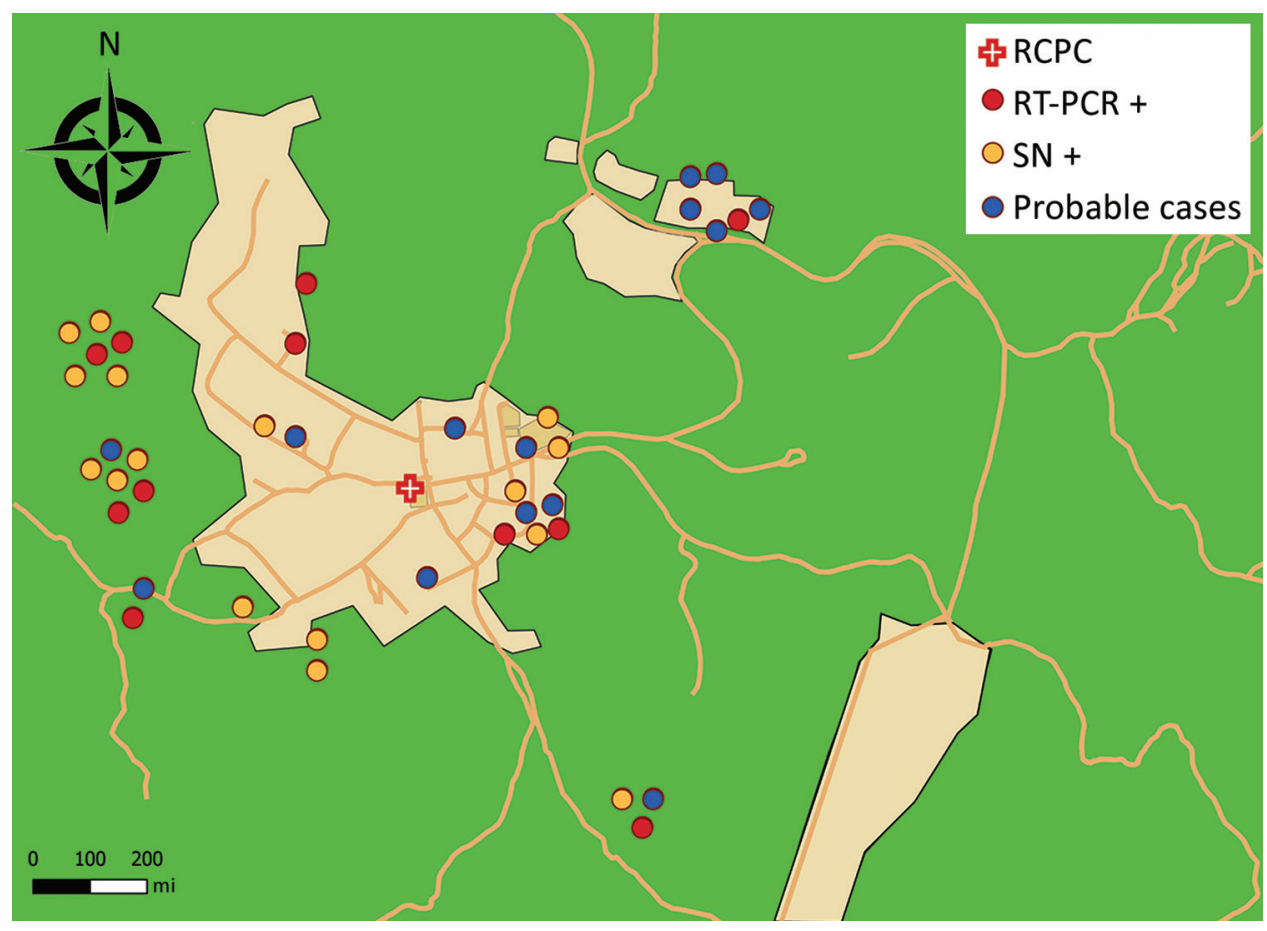

Figure 2. Spatial distribution of patient settlement around the town of Saül, French Guiana, and results of biologic testing for Oropouche virus by testing method. Geolocation is approximate to preserve patient anonymity. For probable cases ( $N=18)$, samples were not taken. Green area, rainforest; light orange area, main districts of Saül; dark orange lines, forest trails. RCPC, remote centers for prevention and care; RT-PCR+, diagnosed with realtime PCR alone $(\mathrm{N}=11)$; $\mathrm{SN}+$, diagnosed with seroneutralization alone $(\mathrm{N}=12)$.

rate $61.1 \%$ (58/95). Few patients had underlying conditions. Symptoms by order of frequency were fever, headache, myalgia, and asthenia (Appendix Table 2). The illness followed 3 successive phases: a 2-4-day acute phase, followed by a remission phase, then a rebound of symptoms $\approx 7-10$ days after onset. Symptom intensity decreased by the end of the second week. Persistent tiredness was reported by $73.2 \%$ patients $(30 / 41)$. Elevated CRP levels of up to $10 \mathrm{mg} / \mathrm{L}$ were observed in $5(23 \%)$ of 22 patients and lymphopenia in $10(42 \%)$ of 24 . The outbreak peaked on September 16 (Figure 2), suggesting that transmission was slowing toward the end of September. The environmental vector control intervention was first applied on September 23 and then again the week of October 6-13. The disease affected all areas of the village of Saül; the index casepatient lived on the forest edge (Appendix Figure).

In total, during 36 nighttime trapping efforts, we collected 254 mosquitoes, 242 (95\%) Culex quinquefasciatus, and 31 Culicoides (biting midges), only 1 of which was $C$. paraensis, which we trapped indoors with a BG trap. We captured the other midge specimens, mostly members of the $C$. guttatus group of subgenus Hoffmania, near a cocoa tree orchard close to the village.

\section{Conclusions}

Since the early 1960s, >30 OROV outbreaks have been reported, mainly in the northern states of Brazil
$(2,3)$, Peru, Ecuador (4), and Trinidad and Tobago, where OROV was first reported in 1955 (5). We report an outbreak of OROV fever in French Guiana. OROV is an arbovirus (genus Orthobunyavirus), transmitted through several vectors, including $C$. paraensis midges and $C x$. quinquefasciatus mosquitoes in the urban cycle and Aedes serratus and Coquillettidia venezuelensis mosquitoes in the sylvatic cycle (6). Vertebrate hosts include sloths (Bradypus tridactylus) and monkeys (Saguinus spp., Saimiri spp., Alouatta spp.) (7). Because vectors and hosts both exist in French Guiana, the report of an OROV outbreak in this country was not unexpected.

OROV PCR is not routinely performed and serodiagnosis is not available in French Guiana; therefore, some individual cases of OROV infection not associated with an outbreak may have gone undetected. However, it is unlikely that many cases from past outbreaks went undiagnosed. Indeed, French Guiana is familiar with arbovirus outbreaks and has the resources to investigate them $(8-10)$. Moreover, the high attack rate, homogeneous distribution of cases across the village, and different age groups affected in this outbreak imply the population had no immunity against OROV. The high attack rate could be explained by Saül's remoteness together with factors related to the COVID-19 pandemic. The village, which is accessible only by air, has been especially affected by the COVID-19 lockdown and subsequent 
movement restrictions, which have isolated it even further. Also, a decrease in army presence in the surrounding forest has led to a substantial increase in illegal gold miners passing through from Brazil, which could have resulted in imported OROV. In addition, unmaintained forest trails around the village may have changed the vector density, but further entomologic studies are needed to test this hypothesis. We captured an abundance of potential vectors, especially $C x$. quinquefasciatus mosquitoes, within the village itself. The low capture yield of local Culicoides spp. midges might have been linked to seasonal trends.

As described in the literature, clinical manifestations were moderately severe, and symptoms recurred among most of the patients studied (11). After the entomologic investigation, vector control measures were implemented in week 40. The near-exclusive presence in the village of $C x$. quinquefasciatus mosquitoes among possible vectors suggests this species as the most plausible vector for this outbreak. However, because vectors were captured and sampled near the end of the outbreak, other potential vectors active earlier cannot be excluded. The presence of $C x$. quinquefasciatus mosquitoes on the coast and in main cities of French Guiana and the geographic expansion of OROV in South America in recent years call for increased epidemiologic surveillance in this region (12).

\section{Acknowledgments}

We thank Séverine Timane Reillon, Frédéric Bouteille, Jean Yves Cattin, Fabien Rogalle, Fanny Gras, Sylvain Fradin, Romuald Carinci, Jean Issaly, Florence Jean Dit Gautier, Antonio Lopez, Mathilde Boutrou, Laure Lemée, David Moua, Laetitia Bremand, Bhety Labeau, Vincent Robert, Solène Wiedner-Papin for their involvement and willingness to help in the composition of this article.

\section{About the Author}

Dr. Gaillet is an infectious diseases specialist and epidemiologist. She created a mobile public health team in isolated communities in the most inaccessible villages of French Guiana, which intervenes on a wide range of public health issues, including the investigation of epidemics and increasing awareness of the prevention of coronavirus disease and many other topics.

\section{References}

1. Naveca FG, Nascimento VAD, Souza VC, Nunes BTD, Rodrigues DSG, Vasconcelos PFDC. Multiplexed reverse transcription real-time polymerase chain reaction for simultaneous detection of Mayaro, Oropouche, and Oropouche-like viruses. Mem Inst Oswaldo Cruz. 2017;112:510-3. https://doi.org/10.1590/0074-02760160062

2. Tilston-Lunel NL, Hughes J, Acrani GO, da Silva DE, Azevedo RS, Rodrigues SG, et al. Genetic analysis of members of the species Oropouche virus and identification of a novel M segment sequence. J Gen Virol. 2015;96:1636-50. https://doi.org/10.1099/vir.0.000108

3. Sakkas H, Bozidis P, Franks A, Papadopoulou C. Oropouche fever: a review. Viruses. 2018;10:10. https:/ / doi.org/ 10.3390/v10040175

4. Wise EL, Pullan ST, Márquez S, Paz V, Mosquera JD, Zapata S, et al. Isolation of Oropouche virus from febrile patient, Ecuador. Emerg Infect Dis. 2018;24:935-7. https://doi.org/10.3201/eid2405.171569

5. Anderson CR, Spence L, Downs WG, Aitken TH. Oropouche virus: a new human disease agent from Trinidad, West Indies. Am J Trop Med Hyg. 1961;10:574-8. https://doi.org/10.4269/ajtmh.1961.10.574

6. Smith GC, Francy DB. Laboratory studies of a Brazilian strain of Aedes albopictus as a potential vector of Mayaro and Oropouche viruses. J Am Mosq Control Assoc. 1991;7:89-93.

7. Pinheiro FP, Travassos da Rosa AP, Travassos da Rosa JF, Ishak R, Freitas RB, Gomes ML, et al. Oropouche virus. I. A review of clinical, epidemiological, and ecological findings. Am J Trop Med Hyg. 1981;30:149-60. https:/ / doi.org/ 10.4269/ajtmh.1981.30.149

8. Mutricy R, Djossou F, Matheus S, Lorenzi-Martinez E, De Laval F, Demar M, et al. Discriminating Tonate virus from dengue virus infection: a matched case-control study in French Guiana, 2003-2016. Am J Trop Med Hyg. 2020;102:195-201. https:// doi.org/10.4269/ajtmh.19-0156

9. Epelboin L, Boullé C, Ouar-Epelboin S, Hanf M, Dussart P, Djossou $\mathrm{F}$, et al. Discriminating malaria from dengue fever in endemic areas: clinical and biological criteria, prognostic score and utility of the C-reactive protein: a retrospective matched-pair study in French Guiana. PLoS Negl Trop Dis. 2013;7:e2420. https:// doi.org/10.1371/journal.pntd.0002420

10. Bonifay T, Prince C, Neyra C, Demar M, Rousset D,

Kallel H, et al.; Char Chik Working group. Atypical and severe manifestations of chikungunya virus infection in French Guiana: A hospital-based study. PLoS One. 2018;13:e0207406. https://doi.org/10.1371/journal.pone.0207406

11. Travassos da Rosa JF, de Souza WM, Pinheiro FP, Figueiredo ML, Cardoso JF, Acrani GO, et al. Oropouche virus: clinical, epidemiological, and molecular aspects of a neglected Orthobunyavirus. Am J Trop Med Hyg. 2017;96:1019-30.

12. Talaga S, Duchemin JB, Girod R, Dusfour I. The Culex mosquitoes (Diptera: Culicidae) of French Guiana: a comprehensive review with the description of three new species. J Med Entomol. 2021;58:182-221.

Address for correspondence: Loïc Epelboin, Unité des Maladies Infectieuses et Tropicales, Centre Hospitalier Andrée Rosemon et Université de la Guyane, Av des Flamboyants, F-97300, Cayenne, French Guiana, France; email: epelboincrh@hotmail.fr 